\title{
Innovative Transport Pressure Management Models for Efficient Transportation Management in the RUDN- University
}

\author{
Margarita Redina ${ }^{1, *}$, Elena Savenkova ${ }^{2}$, Aleksandr Khaustov ${ }^{3}$, Polina Silaeva ${ }^{4}$ \\ ${ }^{1,2,3,4}$ Peoples' Friendship University of Russia, Miklukho-Maklaya str. 6, 117198 Moscow, Russia \\ *corresponding author: redina-mm@rudn.ru
}

\section{Article Info}

Received:

15 March 2021

Accepted:

25 May 2021

Published:

1 June 2021

DOI:

https://doi.org/10.14710/j

sp.2021.11204

\begin{abstract}
The main transport flows on the RUDN territory are caused by the city public and private transport. The general transportation scheme around and through the campus develops some decades. Today this is a huge traffic system with high technogenic pressure on the surrounding ecosystems. The efforts of the university only on the organization of bike transport and shuttle buses cannot protect in this situation our territory. Thus, the university in collaboration with the Moscow government try to solve the transportation problem: a new underground station named RUDN will be built - this must help to optimize transport flows. Transportation management in the university campus (especially situated in the city) needs to apply reliable models for the optimization of transport pressure. That is why, for the RUDNUniversity campus in the South-West of Moscow, we try to develop the most sensitive indicators and to control a set of technogenic factors affecting environmental quality. The unique environmental monitoring system of the RUDN campus able to evaluate the environmental state of the territory and to contribute to maintaining the environmental quality is now under development. The primary results were presented in September 2019 during the first UI Green Metric World Sustainable Campuses Tour in RUDN.
\end{abstract}

\section{Keyword:}

Environmental pressure, pollution, transport, model, management.

\section{Introduction}

Modern universities are large "organisms" with a developed infrastructure, included in the surrounding "environment". Surely, the level of a technogenic pressure on the territory depends strongly on the location of the campus. In the case of the RUDNUniversity it is possible to estimate the location as relative prosperous: this is a city campus 
with a large green zone in the south-west of Moscow city. One of the most significant sources of the environmental impacts is the objects of urban transport infrastructure, including a big highway with a $24 / 7$ load. That is why the regulation of the university's transport infrastructure is in the focus of the university's management. Only such a responsible consideration of this problem allows to protect the state of environmental systems on the campus and to guarantee comfortable conditions for the living of its' population - students and staff.

Currently, the main transport flows inside and outside of the campus are connected with an activity of the public and private transport, mainly these are cars and buses different size. This transport infrastructure has a history of some decades, since the University has got this campus in the 60th Nowadays, this is a combination of transport flows and stationary transport objects (parking, gas stations) that are able to provide a high level of the surrounding ecosystems.

Despite the university try to organize all the possible measures to set the transport infrastructure as rational as possible, to meet all the requirements and recommendations on greening and sustainable transportations, these measures are not enough and cannot compensate for the external transport pressure. Our models for the justification of environmental improvements based on the most modern approaches and own monitoring system data, still show a high level of pollution and a quasi-stress state of some parts of plants in the campus parts near to the roads. This situation leads to the necessity of cardinal changes in the transport infrastructure. The new metro station called RUDN placed virtually in a few steps from the university territory must help to optimize traffic flows.

In the presented material we try to summarize our experience on the estimations of the transport load and on the justification of the reduction of atmospheric pollution due to the reduction of traffic after the metro station opening.

\section{Object Materials and Method}

The object of studying and modelling in the presented material are emissions of transport exhaustions distributed on the territory of the RUDN-University campus. The campus is situated in the South-West of Moscow city, in a relative comfortable (i.e. from the standpoint of the environmental comfortability)districts of Moscow. The main atmospheric pollution source here is the transport flows providing entrance of "macropollutions" like NOx, COx, hydrocarbons etc., as well as "micro-components" like PM particles and supertoxic compounds. The last components, namely polycyclic aromatic hydrocarbons (PAHs) are considered as geochemical markers [1, 2].

Materials used for the modeling in this study are: Results of the accounting of vehicles (evaluation of the transport flow during the day and during the week); Results of sampling in campus and neighbor area: these works were organized in the framework of the project on environmental monitoring of campus; ta data currently include about 4000 measurements of the concentrations of gaseous pollutants, PM, soot in the atmospheric air and in sols; soil moisture and conductivity, electromagnetic fields level, noise level, radioactivity; bioindication results; measurements of PAHs and aliphatic hydrocarbons in snow, soils and parts of plant organisms [3-5].; Data on the project of the construction of the new metro station [6].

To get the adequate model of the transport pressure based on the listed data, we applied the following methodologies:

- Correlation and multivariate classification methods of data analyses principal 
component analyses cluster analyses, multivariate regression (using the software package Statistica and integrated standard procedures in the MS Excel) as instruments of data "pretreatment", filtration, classification;

- Analyses of the dependences between the transport pressure and pollution level, including the spatial distribution of the pollution levels and identification the "risk-zones" caused by the impurities flows from the main sources - roads and parking;

- Application of the data on the geochemical markers - PAHs. These compounds link to the certain environmental process (natural or technogenic) and the indicator ratios of PAHs justify the source of the pollution (i.e., relation between the concentrations of pyrene and fluoranthene or anthracene to phenanthrene), and the presence of some PAHs is a clear evidence of the vehicle activity.

- Standard (state approved) methodologies of the calculation and forecasting of the pollution level because of transport activity (based on the principles of the precautionary: considering the so-called "worst meteorological conditions", that means the worst conditions for the dissemination of impurities in the atmosphere).

\section{Result and Discussion}

Evaluation of the current transport pressure on the campus territory according to the state approved methodology and taking into account the current intensity of the transport activity allowed to get the following assessment of the pollution (Fig. 1, 2). It is to be noted, that the picture presented forecasts the increased level of the environmental risk (calculated as a risk for the human health), exceeding the allowable risk level (red zones). In this case, the forecasted amounts of the pollutants are up to 3 times higher than the permissible level (MPCs of NOx, COx, hydrocarbons...) due to the unfavorable (worst) meteorological conditions preventing the emissions dispersion. In the reality, our monitoring experience during 3 years shows that such the meteorological conditions has been never realized, so we have never measured the concentrations higher than $1.1 \mathrm{MPC}$ on the campus territory.

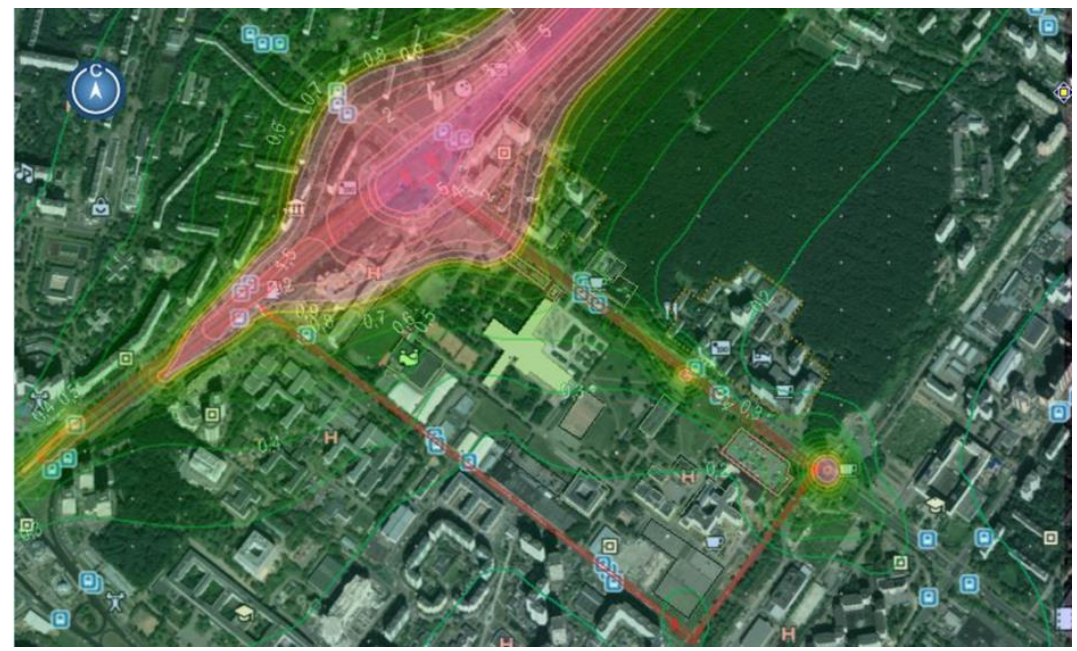

Figure 1. Soot distribution from the main pollution source (highway): the current state 


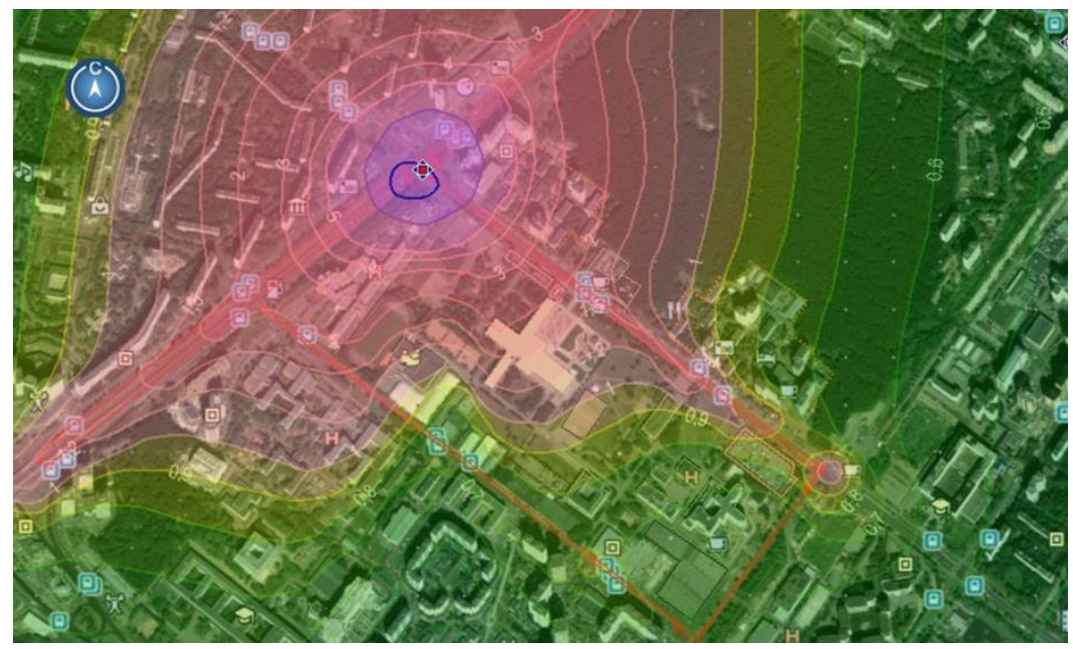

Figure $2 . \mathrm{SO}_{2}$ distribution from the main pollution source (highway): the current state

Thus, the forecasting calculations justify the necessity of the reduction of transport flows as main source of nonconformable environmental situation.

The next stage of the assessment of the transport pressure was the evaluation of scales of pollution area based on the in-situ measurements. Here we apply the approach based on the use of the environmental geochemical markers (PAHs). Using this approach, it was possible to divide the campus area in some zones with the different levels of pollution where vegetation and soils are in different degree "deviated" from the normal state. As example, the spatial distribution of the concentration coefficients (relation of concentration of PAHs in soil and in plant roots) presented on the Fig. 3 shows the "saturation" of natural systems with the pollutants.

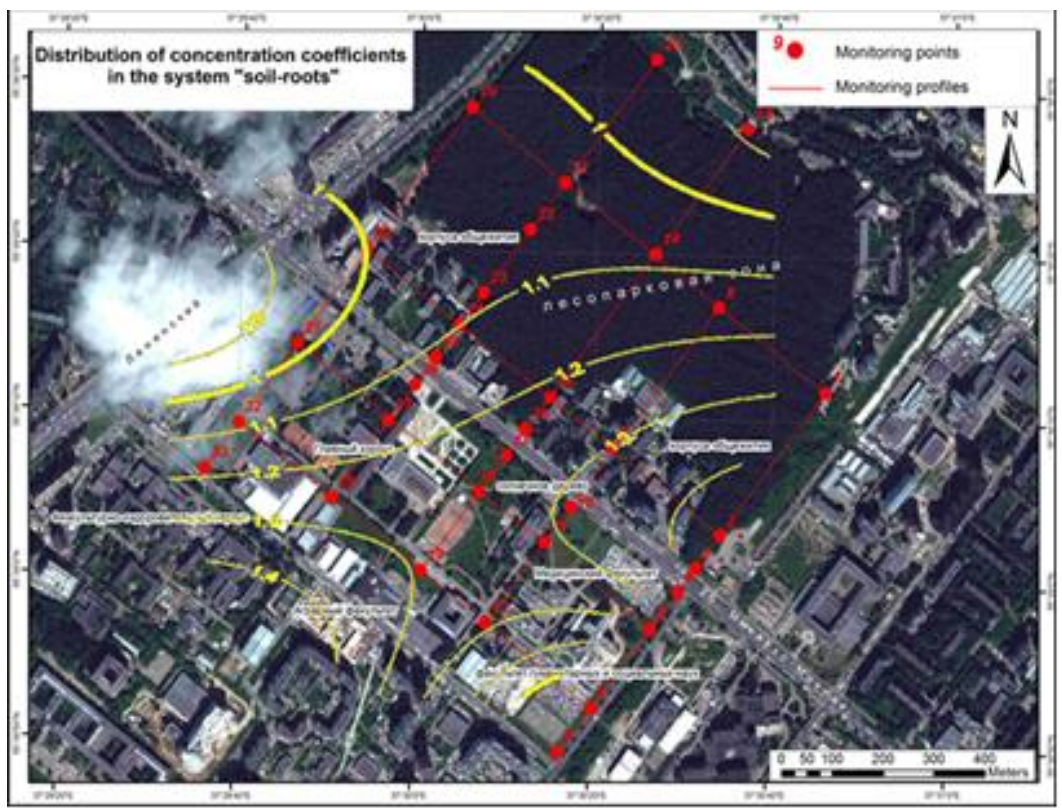

Figure 3. Concentration coefficients: ditribution of PAHS in the system :soil - plant roots" in the campus ares (the current state) 
Thus, modelling results as well as the in-situ measurements of the pollution level in the RUDN-university campus justify a visible level of the transport pressure. Under these conditions it is necessary to manage the situation. But it is clearly that only the university management and staff efforts cannot improve the situation: our transport flows are not due to the "movement activity" of teachers and students, and the cycles and university shuttle-busses cannot reduce the city transport flows outside the campus.

The cardinal change of the problem can be guaranteed by the change of the transport flows - construction of the new underground line with a new metro station in the immediate neighborhood to the campus boarders. The new station is projected with the name of the university ("Universitet Druzhby Narodov" - "Peoples Friendship University"). Estimated passenger flow in the morning rush hour at the entrance is projected on the level of 5.8 thousand people, exit 4.2 thousand people.

Our calculations show, that the transport flows on the main pollution source, the highway Leninsky prospect will be unfortunately virtually not affected. But for the population of the campus (staff and students) and for the nearest residential district the station can become a real way out. The expected reduction of use of private and public vehicles can achieve up to $20 \%$ from the actual level. The additional effect can be caused by the reduction of parking zones: currently the parking zones around the campus as well as on the territory itself are one of the pollution sources (engine idling and warming up stages).

\section{Conclusion}

Transportation management in the university campus (especially situated in the city) needs to apply reliable models for the optimization of transport pressure. That is why, for the RUDN-University campus in the South-West of Moscow, we try to develop the most sensitive indicators and to control a set of technogenic factors affecting environmental quality. The unique environmental monitoring system of the RUDN campus able to evaluate the environmental state of the territory and to contribute to maintaining the environmental quality is now under development. The primary results were presented in September 2019 during the first UI Green MetricWorld Sustainable Campuses Tour in RUDN. Our modelling of the vehicle activity effects and possibility of their reduction show, that the optimal decision for the transport flow management is re-organization of whole the transport infrastructure. That is why, in the case of the considered territory, we expect a very optimistic results for the reduction of transport pressure after the construction of the new metro station.

\section{Summary / Concluding Remarks}

The transportation management of the campus is one of the most efficient instruments of the "greening" of campus. Currently, we face the necessity to redistribute the transport pressure on the campus territory, but in our case, this is not an issue that can be managed by the university itself. Thus, in our opinion, the collaboration of the university with the city government here can bring the optimal result. This experience will be used not only to achieve the "direct effect" of the improvement of the transport situation. We also consider this experience as one of the most interesting examples of the reduction of the urban environmental problems and plan to use it in the educational process. 


\section{References}

1. Eganhouse, Robert P., 2004. Molecular markers and their use in environmental organic geochemistry. The Geochemical Society Special Publications, Volume 9, pp. 143-158.

2. Fabiańska, M., Kozielska, B., Bielaczyc, P., Woodburn, J., \& Konieczyński, J., 2016. Geochemical markers and polycyclic aromatic hydrocarbons in solvent extracts from diesel engine particulate matter. Environmental Science and Pollution Research, Volume 23(7), pp. 6999-7011.

3. Khaustov, A., Boeva, D., 2018. Assessment of the impact of vehicles on the campus of the Peoples' Friendship University of Russia, Bulletin of the Peoples' Friendship University of Russia. Ser .: "Ecology and life safety", Vol 4, pp. 419-430.

4. Khaustov, A., Redina, M., Kenzhin, Zh., Gabov, D., and Yakovleva, E., 2020. Identification of the state of the soil-plant systems on the RUDN-University campus (based on PAH concentrations), E3S Web Conf., Volume 169, 01015, pp. 1-8.

5. Khaustov, A., Redina, M., 2020. Specificity of accumulation of hydrocarbons in various components of geosystems, E3S Web Conf., 169, 01013, pp. 1-8.

6. "Universitet Druzhby Narodov", Kommunarskaya liniya (Peoples' Friendship University, Kommunarskaya line) https://forum.nashtransport.ru/index.php?showtopic $=53552$ 